\title{
Simulation analysis and effect evaluation of excavation and support of underground cavern group
}

\author{
Heng Zhou ${ }^{1,2}$, Peng Huang ${ }^{1,2}$, Shengjie Di ${ }^{1,2^{*}}$ and MingJiang Wang ${ }^{1,2}$ \\ ${ }^{1}$ Northwest Engineering Corporation Limited, Power China, Xi' an, Shanxi, 710065, China \\ ${ }^{2}$ High Slope and Geological Hazard Research \& Management branch, National Energy and Hydropower \\ Engineering Technology R\&D Center, Xi'an, Shanxi, 710065, China
}

\begin{abstract}
According to the main construction procedures of underground caverns, an analysis model for the excavation of a certain pumping station underground cavern group was established, and its excavation and support process are dynamically simulated. The calculation schemes of unsupport and support are compared with indicators such as plastic zone, bolt axial force and displacement field distribution. The analysis results show that after the support, the plastic zone distribution and deformation characteristics of the rock around the cave are greatly improved. The bolt axial force also meets the requirements, indicating that the support parameters and support methods are reasonable. The supporting effect has been well simulated and realized.
\end{abstract}

\section{Introduction}

Underground powerhouse is a construction project under complex geological conditions, and its surrounding rock stability is closely related to the natural geological environment, construction and excavation methods and support methods ${ }^{[1]}$. The excavation of the underground powerhouse can be regarded as a problem of stress release and rebound deformation in mechanics ${ }^{[2]}$. The rock mass where the underground powerhouse is located has an initial geostress field due to factors such as the weight of the rock mass, geological tectonic movement, topography and denudation, and groundwater action [3]. The excavation of the underground powerhouse will release the initial stress of the exposed rock mass at the boundary of the cavern, and further cause the redistribution of the rock mass stress field and displacement field ${ }^{[4]}$. Therefore, the use of reasonable support methods is particularly important for the stability of the surrounding rock of the underground powerhouse chamber group ${ }^{[5]}$.

This paper uses two-dimensional elastoplastic finite element to simulate and analyze an underground powerhouse cavern group to study the distribution law of rock deformation around the cave during the entire excavation process, the development law of the plastic zone, and the change of bolt force. Then evaluate the implementation effect of this supporting measure, providing reference and basis for engineering design and construction.

\section{Engineering simulation and calculation conditions}

\subsection{Engineering Geology Overview}

The cavern of an underground pumping station is buried deep underground, and the thickness of the overlying rock mass is between $500 \mathrm{~m}$ and $550 \mathrm{~m}$. The surrounding rock of the pumping station area is mainly gneiss, with hard rock and layered structure. The surrounding rock is mainly class III, and the local fault fracture zone, fissure dense zone and exit section are classified as type IV, and the overall cave-forming conditions are good. The rock quality of the pumping station area is hard and it is a medium and high in-situ stress area. During the excavation of the cavern, side walls and end walls are prone to flaking, slumping, and micro-rock bursts.

\subsection{Calculation method and calculation model}

The numerical analysis of the overall stability of the surrounding rock adopts two-dimensional elastoplastic finite element calculation. The left boundary, right boundary, lower boundary and upper boundary of the calculation model are more than 3 times the excavation span of the pumping plant house. The overall calculation model is shown in Figure 1. The recommended values of the physical and mechanical parameters of the surrounding rock of the underground pumping station are shown in Table 1. The rock mass parameters in the 
calculation are the intermediate values of the class III rock mass parameters.

Table 1 Suggested values of physical and mechanical parameters of surrounding rock

\begin{tabular}{|c|c|c|c|c|c|c|}
\hline \multirow{2}{*}{$\begin{array}{l}\text { Surrounding rock } \\
\text { category }\end{array}$} & \multirow{2}{*}{$\begin{array}{c}\text { Saturation } \\
\text { Compressive } \\
\text { strength (MPa) }\end{array}$} & \multicolumn{2}{|c|}{ Shear strength } & \multicolumn{2}{|c|}{$\begin{array}{l}\text { Modulus value } \\
\quad(\mathrm{GPa})\end{array}$} & \multirow{2}{*}{$\mu$} \\
\hline & & $f^{\prime}$ & $c^{\prime}(\mathrm{MPa})$ & $E_{\mathrm{o}}$ & $E_{\mathrm{s}}$ & \\
\hline III & $70 \sim 50$ & $0.9 \sim 0.8$ & $1.00 \sim 0.60$ & $12 \sim 10$ & $15 \sim 12$ & $0.28 \sim 0.25$ \\
\hline IV & $50 \sim 30$ & $0.6 \sim 0.4$ & $0.40 \sim 0.30$ & $10 \sim 8$ & $8 \sim 6$ & $0.35 \sim 0.28$ \\
\hline V & $<20$ & $\triangleleft 0.40$ & $\varangle 0.10$ & $<2$ & $<4$ & $>035$ \\
\hline
\end{tabular}

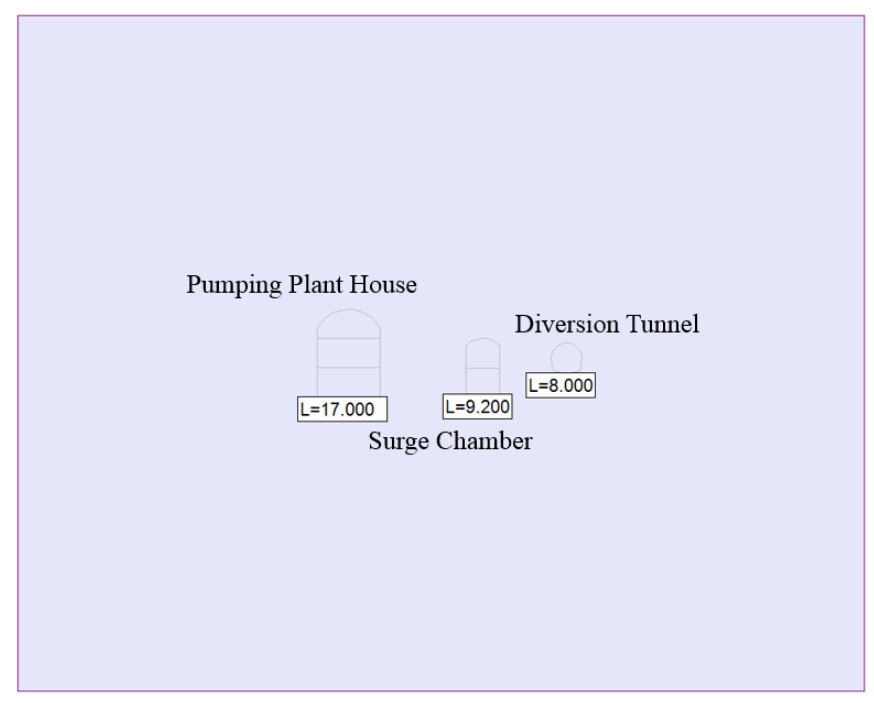

Figure 1. Overall calculation model

\subsection{Calculation plan}

In order to analyze the reinforcement effect of the bolts support measures, the elastoplastic finite element calculation of the staged excavation process under the condition of no support and support is carried out. The entire cavern group is planned to be divided into 4 phases for calculation, and the support method adopts the timely support method when the excavation is completed every time.

According to the engineering analogy, a staged excavation plan was drawn up, see Figure 2. The excavation and support of the diversion tunnel has been completed, and the displacement is cleared after the first step of the excavation and support is completed in the calculation.

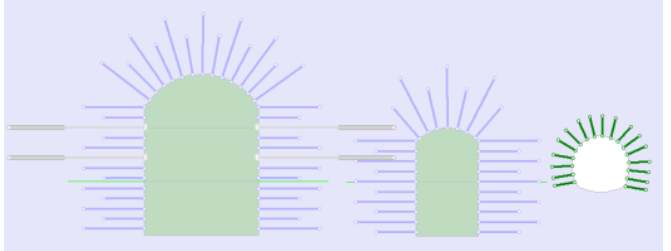

(a) first step

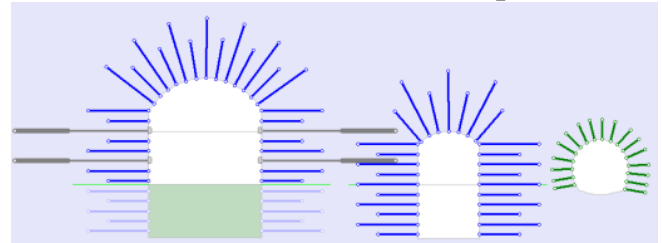

(c) third step

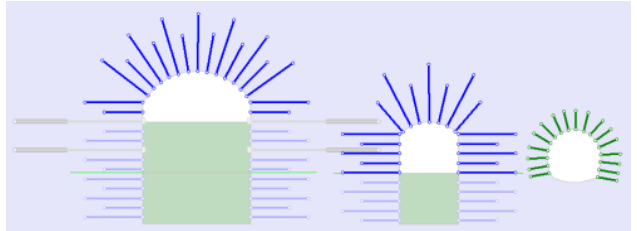

(b) second step

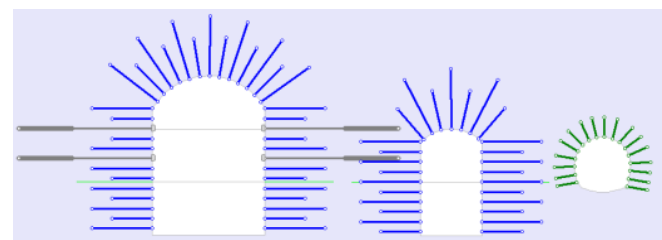

(d) forth step

Figure 2. Distributed excavation support mode 
There are two main calculation schemes:

a) Under the condition of no support, the excavation is calculated in stages. According to the preliminary construction procedure, the pumping plant house is excavated in 3 stages from top to bottom, and the surge chamber is excavated in 2 stages from top to bottom.

b) Carry out phased excavation and phased support calculation for the anchoring support plan drawn up during the construction period. The supporting parameters are: $\Phi$ $28 @ 1.5 \mathrm{~m} \times 1.5 \mathrm{~m}, \mathrm{~L}=6 \mathrm{~m} / 9 \mathrm{~m}$ alternately arranged; 2 rows of $\mathrm{T}=1000 \mathrm{kN}, \mathrm{L}=20 \mathrm{~m}$ prestressed anchor cables on the upstream and downstream walls of the pumping plant house.

\section{Yield criterion of surrounding rock material}

In geotechnical engineering, the most widely used soil failure criterion is the Mohr-Coulumb criterion. If the principal stresses $\sigma_{1}, \sigma_{2}$, and $\sigma_{3}$ are known, and $\sigma_{1} \geq \sigma_{2} \geq \sigma_{3}$ is specified, the Mohr-Coulomb yield condition is expressed as the principal stress:

$$
\frac{1}{2}\left(\sigma_{1}-\sigma_{3}\right)+\frac{1}{2}\left(\sigma_{1}+\sigma_{3}\right) \sin \phi-\cos \phi=0
$$

In the formula: $c$ is the adhesive force, in $\mathrm{MPa}$; $\Phi$ is the angle of internal friction.

This paper adopts the combined failure criterion of shear yield failure based on the Mohr-Coulomb criterion and tensile failure based on the maximum principal stress criterion, as shown in Figure 3.

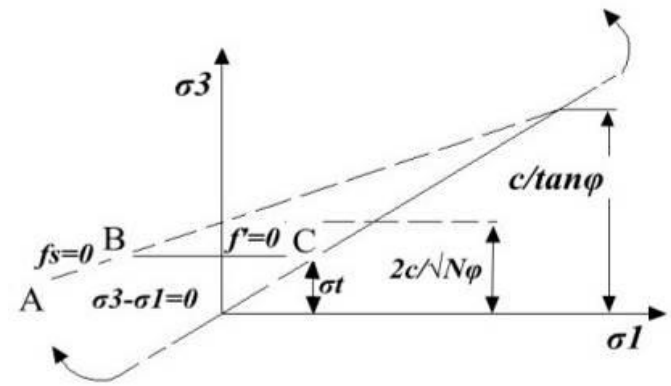

Figure 3. Mohr-Coulumb failure criterion

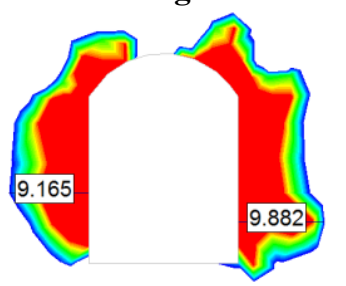

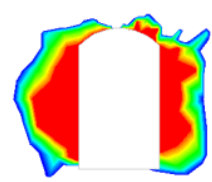

(a) Unsupported

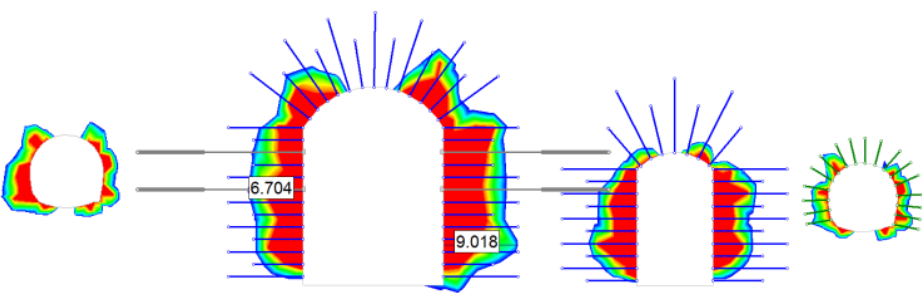

(b) Supported
In the shear yield function, only the maximum principal stress and the minimum principal stress have an effect; the intermediate principal stress has no effect. For the material with internal friction angle $\varphi \neq 0$, its tensile strength cannot exceed, the formula is as follows:

$$
\begin{aligned}
& N_{\Phi}=\frac{1+\sin \phi}{1-\sin \phi} \\
& \text { the shear yield } \\
& \text { ipal stress and the } \\
& \text { the intermediate } \\
& \text { gth cannot exceed, } \\
& \sigma_{\max }^{t}=\frac{c}{\tan \varphi}
\end{aligned}
$$

\section{Comparative analysis of surrounding rock stability simulation}

\subsection{Characteristics of Plastic Zone}

After the anchor support is adopted, the plastic zone of the upper and lower side walls of the pumping plant house develops slowly with the excavation. After the excavation is completed, a certain range of plastic zones appears. Compared with the unsupported excavation, the plastic zone of the top arch, upstream and downstream side walls of the pumping plant house and surge chamber are all reduced. This shows that the use of anchoring support effectively improves the stability of the cavern surrounding rock, and the adopted anchoring support parameters can ensure the stability of the cavern.

Figure 4. Plastic zone

From $\mathrm{B}$ to $\mathrm{C}$ is defined by the tensile failure criterion $f$

In the formula: $\sigma^{t}$ is the tensile strength;
政 $\mathrm{B}$ is fined by the shear failure criterion $f^{s}=0$ :

$$
f^{s}=\sigma_{1}-\sigma_{3} N_{\phi}+2 c \sqrt{N_{\phi}}
$$

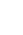

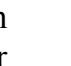




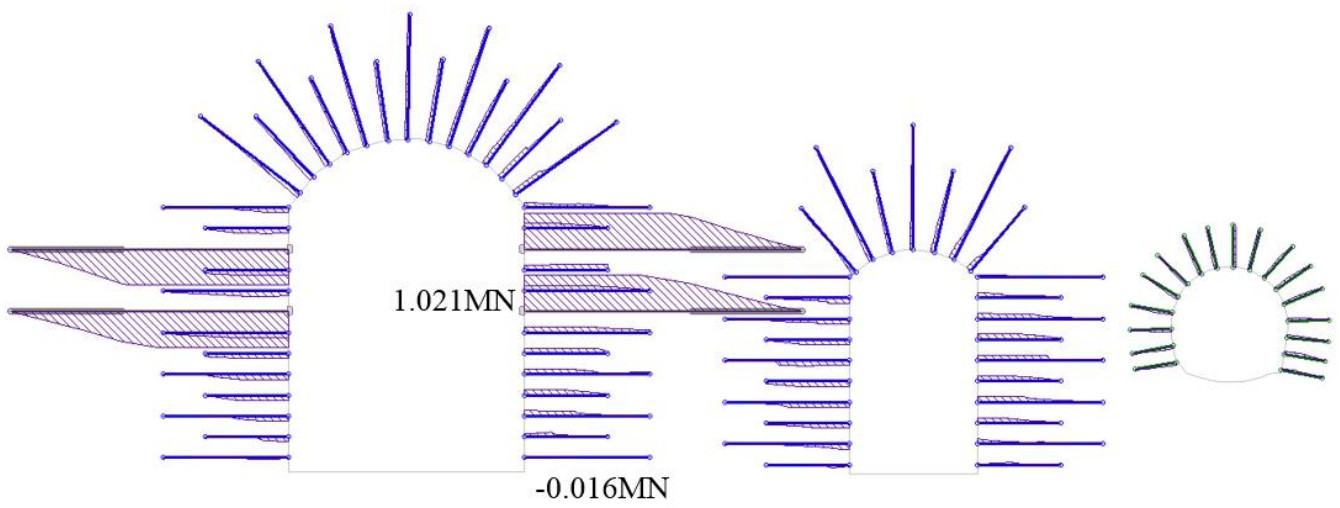

Figure 5. The axial force of bolts

\subsection{Deformation characteristics around the cave}

After the excavation of the cavern, the displacement around the cavern changes to the inside of the cave. Since the surrounding rock of the cavern is relatively complete, the displacement values around the cave are not large. After the excavation is completed, the maximum displacement of the top arch of the pumping plant house appears in the middle of the top arch, and the maximum displacement is $18.0 \mathrm{~mm}$. The maximum displacements of the upstream wall and downstream wall are respectively $10.5 \mathrm{~mm}, 13.5 \mathrm{~mm}$, appear in the middle of the side wall. The maximum displacement of the surge chamber appears in the middle of the top arch, the maximum displacement is $12.0 \mathrm{~mm}$, the maximum displacement of the upstream wall is $9.0 \mathrm{~mm}$, and the maximum displacement of the downstream side wall is $9.0 \mathrm{~mm}$, both Appears in the middle of the side wall. Compared with unsupported excavation, the displacement is reduced.

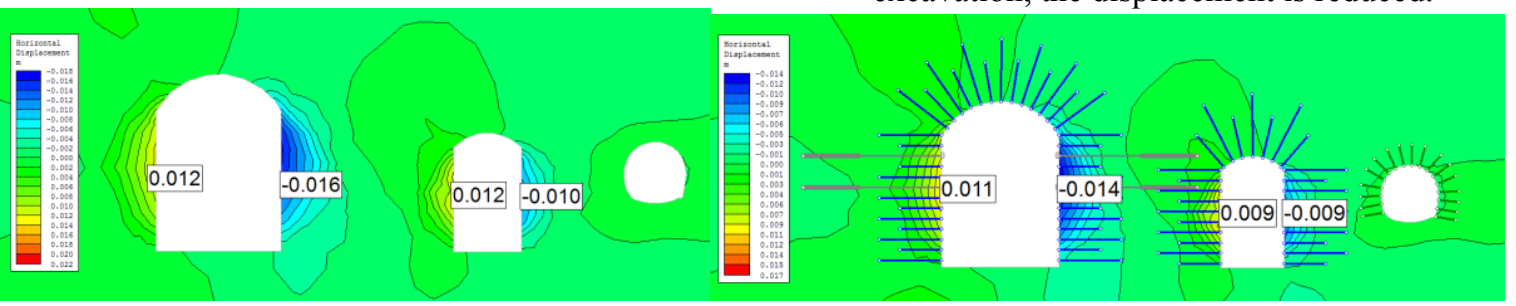

(a) Unsupported

(b) Supported

Figure 6. Horizontal displacement

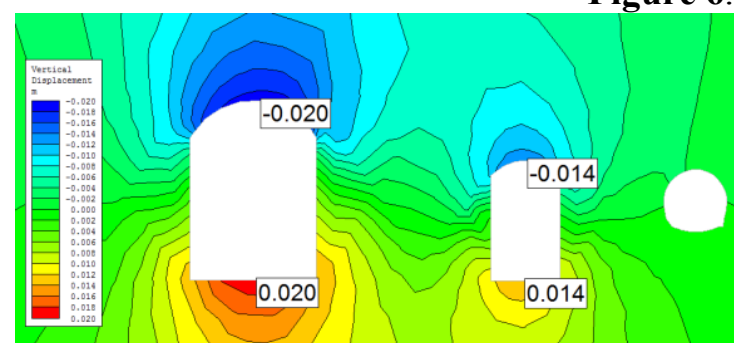

(a) Unsupported

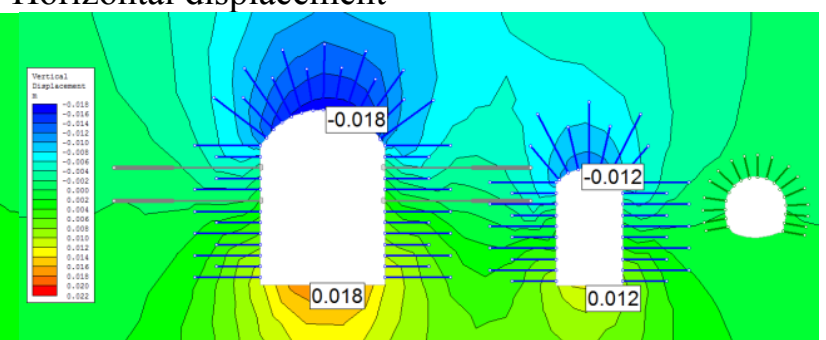

(b) Supported

Figure 7. Vertical displacement

\section{Conclusion}

Using plane nonlinear finite element numerical analysis method, the overall stability of underground caverns is calculated and analyzed. The calculated deformation and plastic zone distribution are more reasonable. According to the engineering geological conditions and calculation results, it can be determined that the overall stability of the surrounding rock of the cavern after the support is guaranteed.

\section{Acknowledgments}

This work was financially supported by the major science and technology project of Northwest Engineering Corporation Limited, Power China. In the meantime, we express thanks to our colleagues for their help and technical support.

\section{References}

1. XIAO Ming. (2000)Three-Dimensional Numerical Model of Construction Process for Underground 
Openin. Chinese Journal of Geotechnical Engineering, 22(4) :421-425.

2. Aydan Ö, Ohta Y, Geniş $M$, et al. (2010)Response and Stability of Underground Structures in Rock Mass during Earthquakes. Rock Mechanics and Rock Engineering, 43(6):857875.

3. Goh A T C, Zhang W. (2012)Reliability assessment of stability of underground rock caverns. International Journal of Rock Mechanics and Mining Sciences, 55:157-163.

4. Karakus M, Fowell R J. (2003)Effects of different tunnel face advance excavation on the settlement by FEM. Tunnelling \& Underground Space Technology,18(5):513-523.

5. Li S, Yu H, Liu Y, et al. (2008)Results from in-situ monitoring of displacement, bolt load, and disturbed zone of a powerhouse cavern during excavation process. International Journal of Rock Mechanics and Mining Sciences, 45(8): 1519-1525. 